\title{
Annotation and validation of genes involved in photosynthesis and starch synthesis from a Manihot full-length cDNA library
}

\author{
Yang ZHANG ${ }^{*}$, Xin CHEN ${ }^{1 *}$, Haiyan WANG ${ }^{*}$, Zhiqiang XIA ${ }^{1}$, Peng LING $^{2}$, Wenquan WANG (凶) ${ }^{1}$ \\ 1 Institute of Tropical Bioscience and Biotechnology, Chinese Academy of Tropical Agricultural Sciences, Haikou 571101, China \\ 2 Department of Horticultural Sciences, Citrus Research and Education Center, University of Florida, Lake Alfred, FL 33850, USA
}

\begin{abstract}
A full-length cDNA library from leaf and root tissues of cassava (Manihot esculenta) Arg7 and one accession of its wild ancestor W14 (M. esculenta ssp. flabellifolia) has been constructed. The library is comprised of four sub-libraries, containing 32640 recombinant clones, 6028 cDNA clones from their $5^{\prime}$ ends, and 128 clones from the $3^{\prime}$ ends were sequenced. In total, 5013 high-quality expressed sequence tags (ESTs) and 1259 unigenes were obtained. Of these, 746 unigenes were identified by their sequence homologies to ESTs from model plants, and 323 unigenes were mapped onto 114 different KEGG pathways. From these, 24 differentially expressed genes involved in starch metabolism and photosynthesis were identified and five of them were selected to compare their expression level between Arg7 and W14. Notably, Arg7 has a higher net photosynthesis rate in leaves, higher ribulose-1,5-bisphosphate carboxylase oxygenase activities in leaves, and higher AGPase activity in roots. This resource is the first EST collection from wild cassava and should be of value for gene discovery, genome annotation and studies of Manihot evolution.
\end{abstract}

Keywords Manihot esculenta, expressed sequence tag, unigene, pathway, expression pattern

\section{Introduction}

Cassava (Manihot esculenta Crantz), an important tropical crop and model plant in the Euphorbiaceae, is an important source of carbohydrates for more than 700 million people, particularly in many developing countries in Africa, Asian and South America ${ }^{[1]}$. Its storage roots are rich in $\operatorname{starch}^{[2]}$,

Received September 8, 2016; accepted October 8, 2016

Correspondence: wangwenquan@itbb.org.cn

${ }^{*}$ These authors contribute equally to the work adapted for survival in barren soil and under drought conditions, and relatively protected from herbivory owing to the presence of cyanogens ${ }^{[3,4]}$. With the current global crisis related to sustainable energy and climate change, interest in cassava has increased, both as a potential resource for bio-fuel to replace oil reserves ${ }^{[5,6]}$ and for its productivity even on land poorly suited to agriculture. Cassava has an unusually high rate of photosynthetic carbon assimilation $\left(\mathrm{CO}_{2}, 43 \mu \mathrm{mol} \cdot \mathrm{m}^{-2} \cdot \mathrm{s}^{-1}\right)$, as well as a high temperature optimum $\left(45^{\circ} \mathrm{C}\right)$ for photosynthesis ${ }^{[7-9]}$. It is reported to have one of the highest rates of $\mathrm{CO}_{2}$ assimilation into sucrose of any plant measured. Although classified as a $\mathrm{C}_{3}$ plant, the leaves exhibit $\mathrm{C}_{3}-\mathrm{C}_{4}$ intermediate behavior under certain conditions, and also exhibit high activity of the $\mathrm{C}_{4}$ enzyme phosphoenolpyruvate carboxylase (PEPC) $)^{[10]}$. The approximate composition of cassava starch on a dry weight basis is $0.24 \%$ ash, $0.13 \%$ fat, $0.49 \%$ protein, $0.15 \%$ crude fiber and $98.4 \%$ starch $^{[11]}$. The molecular mechanisms that control growth and development of cassava, and the complex molecular networks that regulate photosynthesis and starch accumulation in the species, are still far from clear. Therefore, analysis of the cassava transcriptome, especially the expression of the genes related to starch metabolism and other desirable traits, is sorely needed. Large-scale analysis technology, such as the construction of full-length cDNA libraries and the genome-wide sequencing of EST collections, are increasingly being applied to identify related genes and/or pathways. Three full-length cDNA libraries that focus on cassava genes related to tolerance and resistance have already been constructed ${ }^{[12-14]}$. Recently, a cDNA library prepared from root tissue of cassava cv. Huanan 124 at the root bulking stage was constructed to identify genes that regulate starch metabolism ${ }^{[15]}$. Single-pass sequencing of $9600 \mathrm{cDNA}$ clones from this library established a catalog of expressed sequence tags (ESTs) that were assembled into 2878 putative unigenes. All of these EST resources will help to clarify the mechanism of starch accumulation, gene discovery and genome annotation in cassava. 
Several genes that regulate photosynthesis, carbon assimilation, carbon allocation, and starch synthesis have been identified in model plants. The first step in photosynthetic $\mathrm{CO}_{2}$ assimilation and photorespiratory carbon oxidation is catalyzed by ribulose-1,5-bisphosphate carboxylase oxygenase $(\mathrm{RuBisCO})^{[16]}$, and there are high rates of consumption of NADP and NADH during photosynthesis and photorespiration, respectively ${ }^{[17]}$. The carboxylation of phosphoenolpyruvate to yield oxaloacetate and inorganic phosphate is catalyzed by PEPC $(\mathrm{EC} 4.1 \text {. 1.31 })^{[10,18,19]}$. Soluble acid invertase (SAI, EC3.2.1.26) has been suggested to be a key regulator of the accumulation of sucrose, and UDPglucose pyrophosphorylase (UGPase, EC2.7.7.9) converts UDPglucose to glucose-1-phosphate in storage roots ${ }^{[20,21]}$. There are two possible pathways for cleaving cytosolic sucrose. The first involves the conversion of sucrose to glucose and fructose by SAI with the glucose then being phosphorylated by hexokinase. The second is the conversion of sucrose to UDPglucose and fructose, with the UDPglucose subsequently converted to glucose-1-phosphate by UGPase for use in starch synthesis ${ }^{[22]}$. The main enzyme responsible for the synthesis of ADP-glucose, AGPase (EC2.7.7.27), is considered to catalyze the first and key step in starch biosynthesis ${ }^{[23,24]}$. Analysis of transgenic crops using techniques such as quantitative PCR will be essential for identifying and understanding the functions of the full complement of genes involved in these pathways ${ }^{[25]}$.

In this study, we constructed a library of full-length cDNAs prepared from two cassava genotypes. The first, Arg7, is a cultivar of $M$. esculenta characterized by the high starch content $(\sim 32 \%)$ of its tuberous roots. The second, W14, is a selection of $M$. esculenta subsp. flabellifolia, a wild ancestor of $M$. esculenta, which has tuberous roots with low starch content $(\sim 5 \%)$. We used the SMART technology to obtain more full-length transcripts during library construction ${ }^{[26]}$. With the goal of establishing the molecular genetic bases of the substantial differences in root-starch contents between $\operatorname{Arg} 7$ and W14, we constructed cDNA libraries from leaf and root tissues of both varieties. We then used deep sequencing to identify genes that are differentially expressed in the four samples. Although we focused on genes likely to be important in photosynthesis and starch accumulation, availability of the library and the expression information obtained is likely to be of value for improving other aspects of cassava growth and development.

\section{Materials and methods}

2.1 Isolation of total RNA from Manihot root and leaf tissues

Two Manihot species were used in this study. The first was Arg7, a cultivar of M. esculenta with a high starch content
(32\%-34\%) originating from Argentina. The second was W14 a selection of M. esculenta subsp. flabellifolia, the ancestral relative of $M$. esculenta with a low starch content (4\%-5\%) originating from Brazil. Both species were grown under field conditions using standard cultivation methods. Tissues of both species including leaves and roots were collected at 60,120 and 270 days after planting, corresponding to storage root formation, storage root bulking and starch maturity stages. At each sampling three replicate samples were taken from separate individual plants. For leaves, the tip and tenth leaves down the top were sampled, and the petioles were removed before use. For each species, all root-derived samples and all leafderived samples were pooled separately. We used the RNAplant Reagent kit (TIANGEN, Beijing, China) to isolate total RNAs from both Manihot roots and leaves, using the extraction procedure recommended by the manufacturer. The quantity and quality of total RNA extracts were assessed using spectrophotometry and electrophoresis through $1 \%$ agarose gels.

\subsection{Full-length cDNA synthesis and size fractionation}

Before synthesizing first-strand cDNA, total RNAs were treated with DNase to remove contaminating genomic DNA. First-strand cDNA was synthesized from approximately 300 ng purified total RNA using a Creator SMART cDNA Library Construction Kit (DB Clontech, CA, USA) according to the manufacturer's protocol. We used the SMART IV oligonucleotide [5'-AAGCAGTGGTATCAACGCAGAGTGGCCATACGGCCGGG-3'] containing the SfiI A site, and a CDS III/3'PCR primer [5'ATTCTAGAGGCCGCCTCGGCCGACATG-d(T) $30 \mathrm{~N} 1 \mathrm{~N} 3$ ] containing the SfiI B site. The first-strand cDNA product was used as template to synthesize doublestranded cDNA using long-distance PCR. Each PCR reaction was performed using $20 \mathrm{pmol}$ of $5^{\prime} \mathrm{PCR}$ primer [5'-AAGCAGTGGTATCAACGCAGAGT-3'], and 20 pmol of CDS III/3'PCR Primer. Each $50 \mu \mathrm{L}$ PCR mixture contained $2 \mu \mathrm{L}$ of first-strand cDNA product as template, $5 \mu \mathrm{L}$ of $10 \times$ Advantage 2 PCR Buffer, $1 \mu \mathrm{L}$ of $50 \times \mathrm{dNTP}, 1 \mu \mathrm{L}$ of $50 \times$ Advantage 2 polymerase mix, $39 \mu \mathrm{L}$ of deionized $\mathrm{H}_{2} \mathrm{O}$, and $20 \mu \mathrm{L}$ of mineral oil overlaying the PCR mixture. The PCR reaction was performed using a Biometra thermal cycler (Biometra, Horsham, Germany) with the following program: denaturation at $95^{\circ} \mathrm{C}$ for $1 \mathrm{~min}$, followed by 22 cycles of $95^{\circ} \mathrm{C}$ for $15 \mathrm{~s}, 68^{\circ} \mathrm{C}$ for $6 \mathrm{~min}$, and incubation at $10^{\circ} \mathrm{C}$ at the end of cycling. We set up four $50 \mu \mathrm{L}$ mixtures for each RNA sample. The $200 \mu \mathrm{L}$ double-stranded cDNA mixture was extracted with phenol and chlorophenol, and precipitated by adding $20 \mu \mathrm{L}$ of $3 \mathrm{~mol} \cdot \mathrm{L}^{-1}$ sodium acetate, $2.6 \mu \mathrm{L}$ of glycogen $\left(20 \mathrm{mg} \cdot \mu \mathrm{L}^{-1}\right)$ and $520 \mu \mathrm{L}$ of $95 \%$ ethanol. The pellet comprising double-strand cDNA was washed twice with $75 \%$ ethanol, dried and suspended in $79 \mu \mathrm{L}$ of deionized $\mathrm{H}_{2} \mathrm{O}$. 
Double-strand cDNA was incubated with SfiI enzyme at $50^{\circ} \mathrm{C}$ for $2 \mathrm{~h}$, and the reaction mixture contained $79 \mu \mathrm{L}$ of double-strand cDNA, $10 \mu \mathrm{L}$ of $10 \times$ Sfi Buffer, $1 \mu \mathrm{L}$ of BSA $\left(100 \mu \mathrm{g} \cdot \mathrm{mL}^{-1}\right)$ and $10 \mu \mathrm{L}$ of SfiI enzyme (200 U), in a total reaction volume of $100 \mu \mathrm{L}$. The digested doublestranded cDNA was fractionated in a $1 \%$ agarose gel by electrophoresis $\left(6 \mathrm{~V} \cdot \mathrm{cm}^{-1}\right)$ and the size fraction corresponding to fragments between $100 \mathrm{bp}$ and $\sim 6.0 \mathrm{~kb}$ was excised. The excised gel slice was further divided into four pieces, ranging in size from $\sim 500 \mathrm{bp}$ to $\sim 4.0 \mathrm{~kb}$. The digested double-strand cDNA was then extracted and purified from the gel slice by using EZNA gel extraction kit (Omega, CA, USA). The cDNA of each slice was eluted in $50 \mu \mathrm{L}$ of elution buffer, dried, and then resuspended in $8 \mu \mathrm{L}$ of deionized $\mathrm{H}_{2} \mathrm{O}$.

\section{3 cDNA library construction}

The SfiI-digested double-stranded cDNA fragments were ligated to $30 \mathrm{ng}$ pDNR-Lib vector (DB Clontech, CA, USA) with T4 ligase $(0.7 \mu \mathrm{L}=280 \mathrm{U}$, New England Biolabs, USA) in a $16^{\circ} \mathrm{C}$ water incubator overnight or for $16 \mathrm{~h}$. The $10 \mu \mathrm{L}$ ligation product was washed with $75 \%$ ethanol twice to remove salt ions, and dried in a super clean-bench, then suspended in $5 \mu \mathrm{L}$ deionized $\mathrm{H}_{2} \mathrm{O}$. The purified ligation product was transformed into competent DH10B cell using electroporation. Transformed DH10B cells were allowed to recover by incubation in $400 \mu \mathrm{L}$ of SOC medium for 45-60 min with gentle shaking, and then spread onto LB plates containing chloramphenicol $\left(12.5 \mu \mathrm{g} \cdot \mathrm{mL}^{-1}\right)$, and incubated at $37^{\circ} \mathrm{C}$ for $20 \mathrm{~h}$. For the specific pDNR-Lib vector, only clones containing cDNA inserts could grow on the plates. Therefore, all white colonies were regarded as recombinant clones. These colonies were picked and manually transferred into separate wells of 384-well micro-titer plates. Each well of every 384-well plate contained $75 \mu \mathrm{L}$ of freezing storage medium $\left[360 \mathrm{mmol} \cdot \mathrm{L}^{-1} \mathrm{~K}_{2} \mathrm{HPO} 4,17 \mathrm{mmol} \cdot \mathrm{L}^{-1} \mathrm{Na}\right.$ citrate, $4 \mathrm{mmol} \cdot \mathrm{L}^{-1} \mathrm{MgSO}_{4}, 68 \mathrm{mmol} \cdot \mathrm{L}^{-1}\left(\mathrm{NH}_{4}\right)_{2} \mathrm{SO}_{4}, 44 \%(\mathrm{v} / \mathrm{v})$ glycerol, $12.5 \mu \mathrm{g} \cdot \mathrm{mL}^{-1}$ of chloramphenicol, LB]. Colonies were incubated at $37^{\circ} \mathrm{C}$ overnight, and were stored at $-70^{\circ} \mathrm{C}$.

\section{4 cDNA library evaluation and clone sequence analysis}

Forty-eight recombinant clones were randomly selected from each 384-well plate, and grown separately in the $2 \mathrm{~mL}$ wells of 96-well plates each containing $1.0 \mathrm{~mL} \mathrm{LB}$ and $12.5 \mu \mathrm{g} \cdot \mathrm{mL}^{-1}$ chloramphenicol. Plates were incubated overnight at $37^{\circ} \mathrm{C}$ with shaking at $200 \mathrm{r} \cdot \mathrm{min}^{-1}$. We then used colony PCR or digestion of purified plasmid DNA with Hind III and EcoR I to evaluate the recombinant ratio (i.e., the number of PCR reaction clones with inserts divided by total number of PRC reaction clones) and the size of plasmid inserts. We randomly selected $6167 \mathrm{cDNA}$ clones for sequencing analysis. Prior to sequencing, all plasmids were isolated from bacterial clones by cellular lysis and purified in 96-well plates. Single-pass sequencing using the M13 universal primer was used to characterize cDNA inserts from their 5 '-ends.

\subsection{EST sequence data processing}

Original sequence data, as well as trace files, were processed using the Phred base-caller ${ }^{[26-28]}$. Sequences were trimmed using SeqClean software (TIGR Gene Indices Sequence Cleaning and Validation script, available at http://compbio.dfci.harvard.edu/tgi/software) to remove low-quality sequences and sequences derived from rRNA, poly-A tails, bacteria and vectors. All the resulting EST sequences with a sequence length longer than 100 nucleotides were initially clustered using the Megablast program $^{[29]}$, and assembled into contigs by CAP3 assembler with parameters set to identify any match of over 100 nucleotides and identify those spanning at least $95 \%$ of the sequences length ${ }^{[30,31]}$. All of the assembled ESTs were reported as either a singleton with one EST sequence or a contig with at least two overlapping EST sequences.

\subsection{Functional annotation of the sequences}

To compare the homologies of ESTs to known sequences, we performed online Blastn, using a cutoff value of $1 \mathrm{E} \leqslant-5$ to compare the EST collections with entries in the integrative PlantGDB database (http://www.plantgdb.org). Gene annotation was performed using both online Blastx analysis with a cutoff value of $1 \mathrm{E} \leqslant-5$ and comparison with entries in the GenBank protein database (http://www. ncbi.nlm.nih.gov). The top match was selected as the most likely potential homolog for the query EST sequence. Functional categorization and annotation were conducted as Gene Ontology (GO) annotation ${ }^{[30,31]}$ (http://geneontology.org). The Kyoto Encyclopedia of Genes and Genomes (KEGG) pathway database (http://www.genome.jp/kegg/) was used to assign genes to metabolism pathways using Blast2GO software ${ }^{[32]}$ (https://www.blast2go.com).

\subsection{Quantitative RT-PCR analysis}

Total RNA used for quantitative RT-PCR was extracted from leaf and root samples using the method described above. For leaf tissue, we sampled unfolded leaves from the top two branches of $200 \mathrm{~d}$ old plants at six sampling times (once every $2 \mathrm{~h}$, from 8 am to $6 \mathrm{pm}$ ). We took samples from three Arg7 individuals and two W14 individuals at each time point, and samples taken at the same time point from different individuals were pooled. We extracted RNA from 12 leaf samples altogether. We sampled storage roots from Arg7 plants that were 120, 160 and $200 \mathrm{~d}$ old. Roots of three individuals at the same time point were pooled. All fibrous root samples were also 
pooled. Owing to the low frequency of storage roots in W14, we obtained only one storage-root sample from a 200 d old W14 plant. Altogether, we extracted RNA from five different root samples.

All qRT-PCR reactions were performed using a 6200HRM Corbett Life Science Rotor-Gene 6000 instrument (Corbett Research, Germany) with SYBR Premix Ex $\mathrm{Taq}^{\mathrm{TM}}$ (TaKaRa Biotechnology Co., Ltd, Dalian, China), according to the manufacturer's instructions. We used Primer Premier 5.0 and Vector NIT 11.0 software (Applied Biosystems) to design primers based on the sequences of key genes of interest identified in our library. Whenever unigene sequences differed between the two species, the region with the highest homology was used for primer design. The average size of PCR products was approximately $170 \mathrm{bp}$. The cassava actin gene was used as an internal control. The sequences of primers used in this study are provided in Table 1.

Real-time PCR was performed following a standard SYBR Premix Ex TaqTM kit (TaKaRa) protocol. The reactions $(1.0 \mu \mathrm{L}$ first-strand cDNA product, $1 \times$ Universal PCR Master Mix, $1.0 \mathrm{mmol} \cdot \mathrm{L}^{-1}$ primers) were set up in $0.1 \mathrm{~mL}$ tubes of the Rotor-gene 6000 machine (QIANGEN, Hilden, Germany). The procedure for thermal cycling involved incubation at $95^{\circ} \mathrm{C}$ for $10 \mathrm{~s}$, followed by 40 cycles of a program involving incubation at $95^{\circ} \mathrm{C}$ for $5 \mathrm{~s}$, then $56^{\circ} \mathrm{C}$ for $15 \mathrm{~s}$ and finally, $72^{\circ} \mathrm{C}$ for $15 \mathrm{~s}$. The procedure ended with a melt-curve ramping from 60 to $95^{\circ} \mathrm{C}$, with temperature increases of $0.5^{\circ} \mathrm{C}$ at each step. Real-time PCR reactions were repeated six times for leaf samples and nine times for root samples. The relative mRNA level was calculated as $2^{-\Delta C_{\mathrm{T}}}$. Correlation analysis and significance analysis were carried out using SPSS 17.0 software.

\subsection{Evaluation of light intensity and net photosynthetic rate}

The intensity of sunlight was determined using a HT4GLZ-B photosynthetically active radiation meter HT4GLZ-B (Zhongxi, Inc, Shengyang, Liaoning, China). The net photosynthetic rate $(\mathrm{Pn})$ was determined using an LI6400XT instrument (LI-6400: LI-COR, Inc, Lincoln, NE, USA).

\section{Results}

3.1 Construction and validation of the cDNA library in cassava

A full-length cDNA library was constructed from RNA extracted from leaves and roots of two Manihot species, cv. Arg7 (tuber starch content 32\%) and its wild ancestral relative W14 (tuber starch content 4\%-5\%). The library comprises 32640 recombinant clones, with cDNA inserts having an average length of approximately $0.6 \mathrm{~kb}$, ranging from 0.4 to $1.1 \mathrm{~kb}$. In this library, only $60 \%$ of the sequences include a poly-A tail, although single-pass sequencing was only initiated from the $5^{\prime}$ ends of the cDNA inserts. The recombinant ratio of the cDNA library was $92 \%$.

We sequenced 6028 randomly selected clones from their $5^{\prime}$ ends and 128 clones from their $3^{\prime}$ ends, generating 5593 reads in total, in which 3235 reads were derived from $\operatorname{Arg} 7$

Table 1 Genes of interest, primers and size of amplification products

\begin{tabular}{|c|c|c|c|c|}
\hline Gene cellular activity & $\begin{array}{l}\text { Abbrevia- } \\
\text { tion }\end{array}$ & EST sequence source & Forward/Reverse primer & Amplicon size/bp \\
\hline $\begin{array}{l}\text { RuBisco (Ribulose-1,5-bisphosphate } \\
\text { carboxylase oxygenase) }\end{array}$ & MerbcS & $\operatorname{Arg} 7$ & $\begin{array}{l}\text { 5'-TGGCAGCTTCCACATTGTC-3' } \\
\text { 5'-CTCATACCTTCCACCACTCTCA-3' }\end{array}$ & 175 \\
\hline Ferredoxin:NADP ${ }^{+}$oxidoreductase & $M e \mathrm{FNR}$ & $\operatorname{Arg} 7$ & $\begin{array}{l}\text { 5'-CGCTCTCTAGTGCCATGTTTAG-3' } \\
\text { 5'-GCACTCTATTTCCACTTCACCC-3' }\end{array}$ & 185 \\
\hline $\begin{array}{l}\text { NADH dehydrogenase (quinone } \\
\text { reductase) }\end{array}$ & Mendh & $\operatorname{Arg} 7$ & $\begin{array}{l}\text { 5'-ATTCCAGCCAAGATGACGG-3' } \\
\text { 5'-ACAGAATTTAGTGAGCGGCG-3' }\end{array}$ & 151 \\
\hline $\begin{array}{l}\text { PEPC (Phophoenolpyruvate carboxy- } \\
\text { lase) }\end{array}$ & Meppc & Arg7/W14 & $\begin{array}{l}\text { 5'-CGGATCAACGGGAAGCAAGA-3' } \\
\text { 5'-GCAAGATGAGTGGGTCCTCC-3' }\end{array}$ & 196 \\
\hline $\begin{array}{l}\text { AGPase (adenosine } 5 \text { '-diphosphate } \\
\text { glucose pyrophosphorylase) }\end{array}$ & $M e \mathrm{LSU}$ & W14 & $\begin{array}{l}\text { 5'- AATCCAGATAATCCATTCGG-3' } \\
\text { 5'- TAGCAGCAACTCAAACGCCT-3' }\end{array}$ & 165 \\
\hline $\begin{array}{l}\text { UGPase (UDPglucose pyrophosphor- } \\
\text { ylase) }\end{array}$ & MeUGP & $\begin{array}{l}\text { Jatropha curcas (GenBank: } \\
\text { GT973508.1) }\end{array}$ & $\begin{array}{l}\text { 5'- GGCTTGTAGAATCCGACGCA-3' } \\
\text { 5'- AGTTGCCTTCACTGGAAGGA-3' }\end{array}$ & 170 \\
\hline SAI (soluble acid inverse) & MeInv & Provided by Dr. Peng Zhang" & $\begin{array}{l}\text { 5'-ATCTACGACACCGAGGACTTCAT-3' } \\
\text { 5'-CTGTTCAATTCATCGTAAGTTCCA-3' }\end{array}$ & 151 \\
\hline \multicolumn{5}{|l|}{ Constitutive control gene } \\
\hline Actin & MeAct & & $\begin{array}{l}\text { 5'-CGATGGTCGTACAACTGGTAT-3' } \\
\text { 5'-ATCCTCCAATCCAGACACTGT-3' }\end{array}$ & 450 \\
\hline
\end{tabular}

Note: \#, Shanghai Center for Cassava Biotechnology, Institute of Plant Physiology and Ecology, Shanghai Institutes for Biological Sciences, Chinese Academy of Sciences, China. 
Table 2 Summary of library properties and assembly results after sequencing the clones and their distributions among cDNA sub-libraries

\begin{tabular}{|c|c|c|c|c|c|}
\hline \multirow{2}{*}{ Category } & \multirow{2}{*}{ Library } & \multicolumn{4}{|c|}{ Sub-library } \\
\hline & & Arg7 leaf & Arg7 root & W14 leaf & W14 root \\
\hline No. of clones sequenced & 6176 & 1082 & 2413 & 615 & 2066 \\
\hline EST & 5593 & 1038 & 2197 & 438 & 1920 \\
\hline Analyzed EST > 100 bp & 5067 & 964 & 1995 & 391 & 1717 \\
\hline Cluster & 1153 & 195 & 746 & 157 & 322 \\
\hline Contig & 476 & 62 & 256 & 47 & 143 \\
\hline Singlet & 783 & 145 & 538 & 114 & 213 \\
\hline Unigene & 1259 & 207 & 749 & 161 & 356 \\
\hline ORF prediction & 1093 & 188 & 658 & 133 & 336 \\
\hline
\end{tabular}

and 2358 reads were derived from W14 (Table 2). The resulting sequences were processed using the base-calling program 'Phred' (http://www.phrap.com/phred/) with satisfactory quality standards (100 nt of Q16, corresponding to an approximate error probability of 0.01$)^{[33]}$. This generated 5013 high-quality EST sequences (more than $100 \mathrm{bp}$ of EST sequence after removal of vector sequences, NCBI access numbers JK733886 to JK738898), of which 2671 included poly-A tail sequences. The lengths of ESTs ranged from 100 to $1003 \mathrm{bp}$, with an average length of $556.4 \mathrm{bp}$. The 5013 high-quality EST sequences clustered into 1153 clusters, in accordance with UniGene (http:// www.ncbi.nlm.nih.gov/unigene) classification, and were further assembled into 476 contigs and 783 singletons using CAP3. The contigs and singletons represented 1259 putative unigenes with an average length of $563.2 \mathrm{bp}$. The longest unigene was $2380 \mathrm{bp}$. The percentage redundancy for each library varied between $79 \%$ (W14 root) and 58\% (W14 leaf). The recombinant ratio of the whole library was $92 \%$.

The information in the CAP3 assembly that we used to build a cluster profile represents the number of ESTs per assembled unigene (Fig. 1). Most (62.16\%) of the unigenes had only one EST sequence. The analysis of the 5013 ESTs collection from this work revealed an average GC-content of $44.26 \%$, ranging from $13.6 \%$ to $73.8 \%$.

\subsection{Functional categorization and reconstruction of metabolic pathways}

GO analysis based on sequence similarity, enabled us to assign the 1259 unigenes to KEGG metabolic pathways $^{[34]}$. We matched $746(59.3 \%)$ of the unigenes to ESTs from model plants (considered as known genes), whereas $513(49.7 \%)$ of the unigenes had no function assigned. Overall $323(25.76 \%)$ of the unigenes were assigned to 114 different pathways, with some unigenes assigned to more than one pathway. As shown in Table 3, unigenes were assigned to all five major categories of the KEGG pathway: metabolism (176 unigenes), genetic information processing (48 unigenes), processing of environmental information ( 25 unigenes), cell processing ( 25 unigenes) and human diseases (58 unigenes).

The number of unigenes mapped to KEGG pathways differed substantially between the four sub-libraries (Appendix A, Table S1). For the carbohydrate metabolism and energy metabolism pathways we focused on in our study, we found significant differences in pathways related to photosynthesis, carbon fixation in photosynthetic organisms, glycolysis/gluconeogenesis, and oxidative phosphorylation (Fig. 2). Only six unigenes mapped to the starch and sucrose metabolism pathway, of which three, the genes encoding AGPase, sucrose synthase and starch branching enzyme, are important in starch synthesis.

Of the 103 unigenes predicted to function in carbohydrate and energy metabolism, 23 were only found in one of the four sub-libraries. Of these 23 unigenes, 14 were unique to $\operatorname{Arg} 7$ (with seven unigenes expressed in leaf tissue and seven in roots), and nine were unique to W14 (with two unigenes expressed in leaf tissue and seven in roots). Six unigenes that encode enzymes involved in carbohydrate metabolism were found in the Arg7 root sublibrary, compared with only four in the W14 root sublibrary. However, the AGPase unigene was only found in the W14 root sub-library. It is interesting that three unigenes encoding important photosynthetic enzymes (NADH dehydrogenase, ferredoxin: NADP + oxidoreductase and RuBisCO) were only found in the Arg7 leaf sublibrary. The unigenes that encode enzymes involved in specialized metabolic pathways, such as acetohydroxyacid synthase (butanoate metabolism), phospholipase C (inositol phosphate metabolism) and donor: $\mathrm{H}_{2} \mathrm{O}_{2}$-oxidoreductase (methane metabolism), were found mainly in the sublibrary prepared from W14 root tissue.

\subsection{Differential expression of genes involved in photosynthesis and starch metabolism}

To further understand the differential expression of genes involved in photosynthesis and starch metabolism in Arg7 


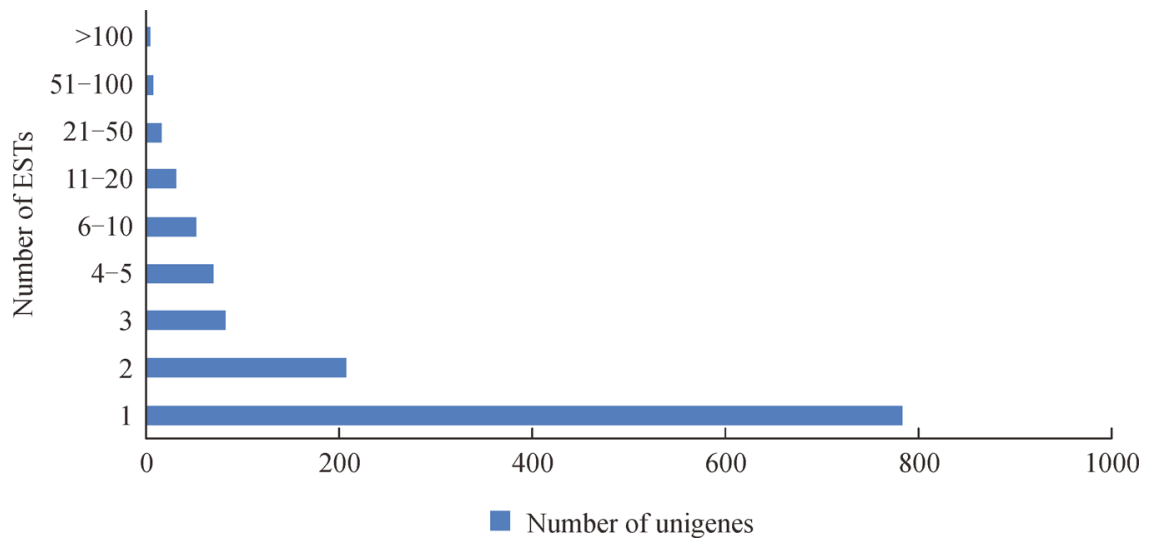

Fig. 1 Analysis of cassava ESTs assembled in terms of the number of ESTs per unigene. A total of 783 unigenes were represented by a single EST.

Table 3 The 323 unigenes mapped to KEGG pathways

\begin{tabular}{|c|c|c|c|}
\hline KEGG pathway & No. of pathways mapped & No. of genes & Total genes mapped $/ \%$ \\
\hline Metabolism & 69 & 176 & 54.49 \\
\hline Amino acid metabolism & 8 & 12 & 3.72 \\
\hline Biosynthesis of secondary metabolites & 6 & 8 & 2.48 \\
\hline Carbohydrate metabolism & 15 & 51 & 15.79 \\
\hline Energy metabolism & 8 & 52 & 16.10 \\
\hline Glycan biosynthesis and metabolism & 5 & 6 & 1.86 \\
\hline Lipid metabolism & 8 & 13 & 4.02 \\
\hline Metabolism of cofactors and vitamins & 7 & 11 & 3.41 \\
\hline Metabolism of other amino acids & 3 & 4 & 1.24 \\
\hline Nucleotide metabolism & 2 & 11 & 3.41 \\
\hline Xenobiotics biodegradation and metabolism & 7 & 8 & 2.48 \\
\hline Genetic information processing & 8 & 48 & 14.86 \\
\hline Folding, sorting and degradation & 4 & 8 & 2.48 \\
\hline Replication and repair & 2 & 2 & 0.62 \\
\hline Transcription & 4 & 38 & 11.76 \\
\hline Environmental information processing & 8 & 16 & 4.95 \\
\hline Membrane transport & 2 & 2 & 0.62 \\
\hline Signal transduction & 6 & 14 & 4.33 \\
\hline Cellular processes & 13 & 25 & 7.74 \\
\hline Cell communication & 2 & 3 & 0.93 \\
\hline Cell growth and death & 3 & 7 & 2.17 \\
\hline Cell motility & 1 & 3 & 0.93 \\
\hline Endocrine system & 4 & 9 & 2.79 \\
\hline Nervous system & 2 & 2 & 0.62 \\
\hline Sensory system & 1 & 1 & 0.31 \\
\hline Human diseases & 14 & 58 & 17.96 \\
\hline Cancers & 6 & 8 & 2.48 \\
\hline Immune disorders & 1 & 9 & 2.79 \\
\hline Infectious diseases & 2 & 8 & 2.48 \\
\hline Metabolic disorders & 1 & 4 & 1.24 \\
\hline Neurodegenerative diseases & 4 & 29 & 8.98 \\
\hline
\end{tabular}




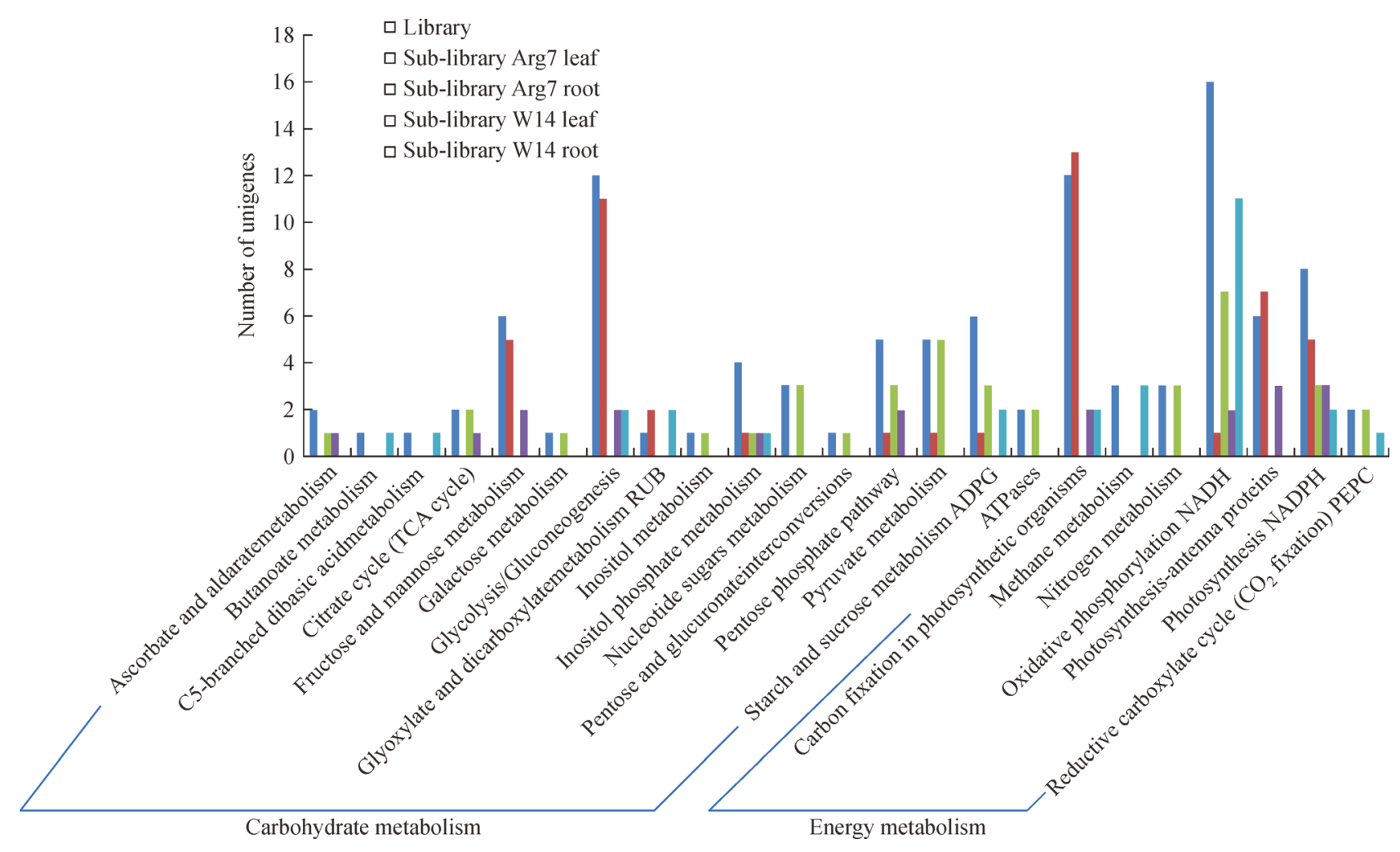

Fig. 2 The differential distribution of annotated unigenes in different pathways related to carbohydrate and energy metabolism among the four sub-libraries.

and W14, we selected five key genes, which were found in only one of the four sub-libraries and compared their general expression between Arg7 and W14. Of these four genes, those encoding PEPC, NADH dehydrogenase (NADH:ubiquinone reductase, EC1.6.5.3), and ferredoxin-NADP + oxidoreductase (EC1.18.1.2) were from the Arg7 leaf and root sub-libraries. The remaining gene, which encodes AGPase, was from the W14 root sublibrary. Other key regulators of sucrose accumulation that we studied were SAI and UGPase. The genes encoding these enzymes (and abbreviations used for this in this paper) are listed in Table 1.

\subsection{Daily expression pattern of genes related to} photosynthesis in leaves

Compared with its wild ancestor, W14, Arg7 has both a higher Pn (Fig. 3) and higher starch content in storage roots (32\%-34\% compared with $4 \%-5 \%$ in W14). Figure 4 compares the expression patterns of five genes at six time points during the day. Expression of the $M e$ FNR gene was higher and better correlated $(P<0.0 .5)$ with ambient light intensity in Arg7 plants than in W14 plants (Fig. 4a; Appendix A, Table S1). Expression of $M e$ FNR was highest at 10 am in both Arg7 and W14, and significantly lower at the five other time points examined (Fig. 4b). The expression levels at noon and $2 \mathrm{pm}$ were higher than at the other four times in Arg7 and higher than at any time in

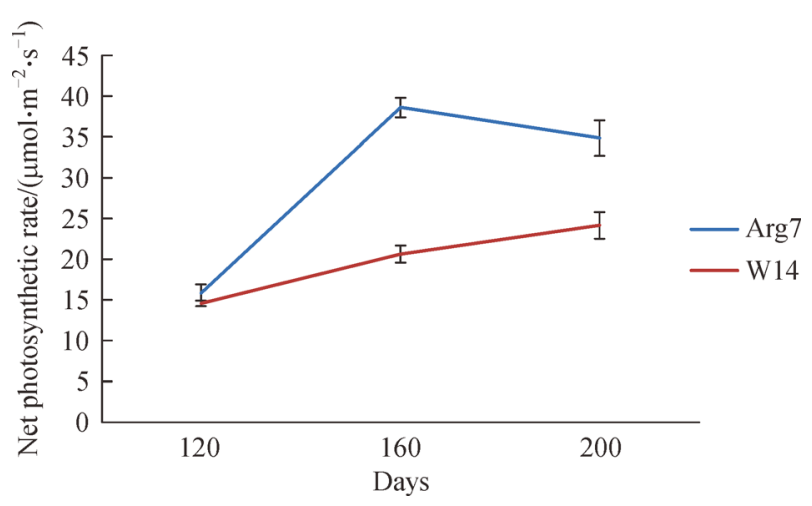

Fig. 3 Net photosynthetic rates in the leaves of Arg7 and W14 during the growing period 120, 160, and $200 \mathrm{~d}$ after planting. All measurements were made at 10:00 am. Each data point represents the mean $\pm \mathrm{SD}$ of three replicates.

W14, but its expression levels in W14 were significantly higher than those in Arg7 at 10 am and 6 pm (Fig. 4c). The expression of $M e \mathrm{FNR}$ was significantly correlated with light intensity $(P<0.05)$. Given the high rates of consumption of NADP during photosynthesis and NADH during photorespiration ${ }^{[17]}$, levels of expression of $M e$ FNR in leaves are likely to influence the catalytic activity of RuBisCO, which has both carboxylase and oxygenase activities. In this regard, it is notable that the 

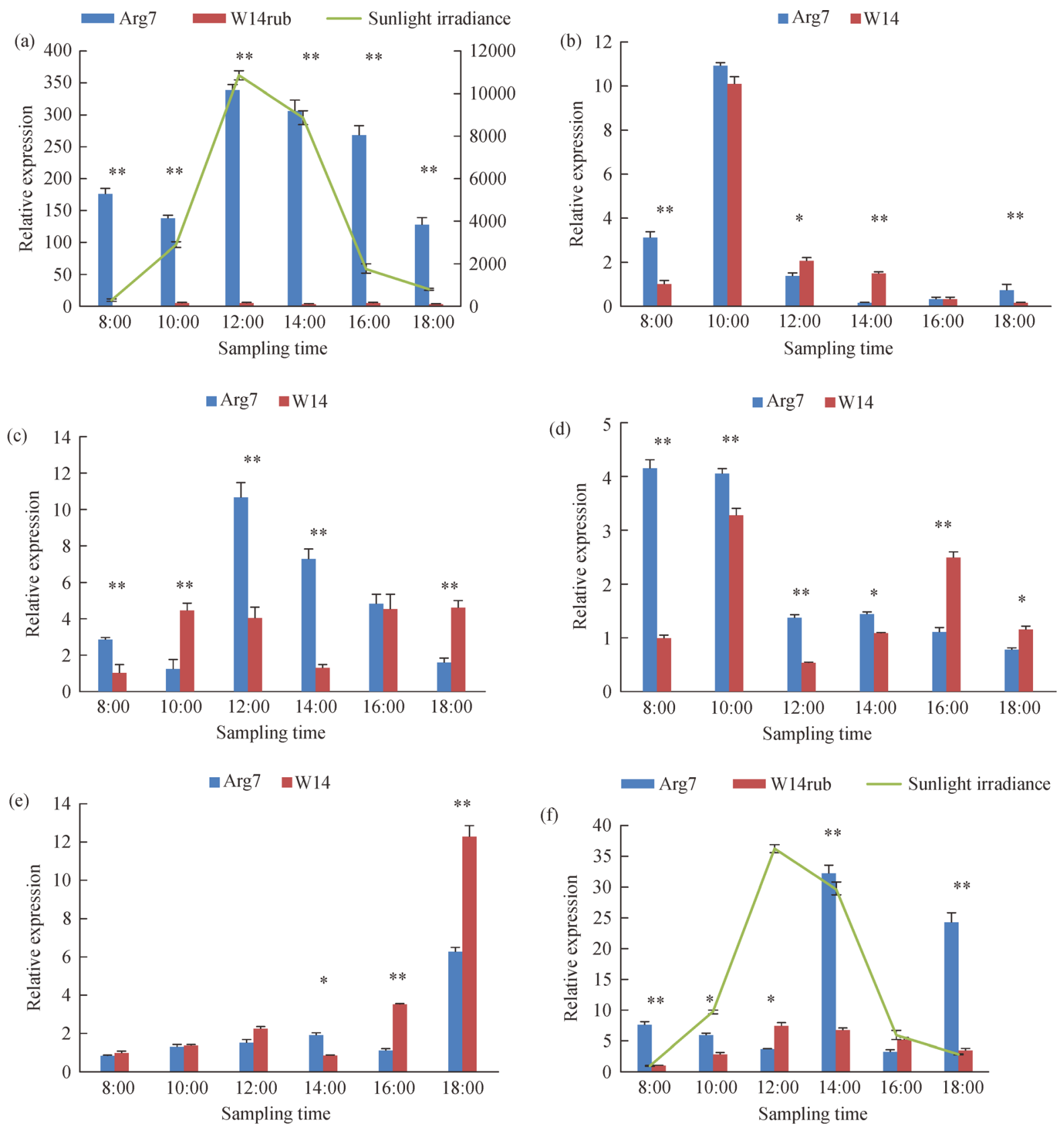

Fig. 4 Diurnal fluctuations in the expression of selected genes in cassava leaves measured using real-time PCR, with variations in transcript levels associated with changes in light intensity between 8:00 h and 18:00 h. (a) MerbcS; (b) MeFNR; (c) Mendh; (d) Meppc; (e) MeLSU; (f) MeInv. Each data point represents the mean \pm SD of nine replicates, with values indicating fold-changes in relative gene expression following normalization relative to the actin cassava gene. Asterisks above each bar indicate the degree of significance differences in the expression levels between the Arg7 cultivar of Manihot esculenta and the W14 variety of Manihot flabellifolia $(*, P<0.05 ; * *, P<0.01)$.

changes in the expression levels of MerbcS and were significantly correlated $(P<0.01)$.

Real-time PCR analysis indicated that the expression of $M e \mathrm{PPC}$ was higher in $\mathrm{Arg} 7$ than in W14 from 8 am to $2 \mathrm{pm}$, but lower at 4 and $6 \mathrm{pm}$ (Fig. 4d). This result is consistent with higher levels of PEPC activity in leaves of $\operatorname{Arg} 7$ than in those of W14, and the observation of distinct, green bundle sheath cells in leaves of Arg7 but not in leaves of W14 (unpublished data). These observations suggest that PEPC fixes more $\mathrm{CO}_{2}$ in $\mathrm{Arg} 7$ than in W14. The high rates of photosynthesis in individual leaves and existence of distinct green bundle sheath cells in leaves of certain Manihot species suggest that cassava leaves possess some novel photosynthesis characteristics ${ }^{[33,35]}$. In both varieties, expression of MeLSU increased from 8 am to $6 \mathrm{pm}$, and at $4 \mathrm{pm}$ in Arg7 (Fig. 4e). 
The enzyme responsible for the synthesis of ADPglucose, AGPase, is considered the first and key step in starch biosynthesis. Starch synthesized during the day in leaves is temporarily stored in chloroplasts, and then degraded to sucrose at night for transport to $\operatorname{roots}^{[36,37]}$. Levels of expression of MeINV were fairly consistent in Arg7 over most of the time points measured, but with peaks in transcript at 2 and $6 \mathrm{pm}$. For W14, trends in the expression of $M e \mathrm{INV}$ transcripts were significantly related to light intensities, although levels were generally lower than those observed in Arg7 (Fig. 4f). SAI has been suggested to be a key regulator of sucrose accumulation. In leaves, reducing sugars produced from photosynthetically generated sucrose support leaf growth and are partly transported to sink organs for storage. Accordingly, high acid invertase activities always follow high rates of plant growth $^{[38]}$. Sucrose export from leaves is higher during the day than the night ${ }^{[39]}$. Near the end of the day $(6 \mathrm{pm})$, the content of sucrose in leaves was nearly at its highest level ${ }^{[40]}$, increased expression of $M e \mathrm{INV}$ and $M e \mathrm{LSU}$ transcripts was likely attributable to their regulation by cellular osmotic pressure. Moreover, the efficiency of photosynthesis was greatest at midday under the highest light intensity. This likely increased sucrose levels, which in turn likely accounts for the upregulated expression of $\mathrm{MeINV}$ at $2 \mathrm{pm}$ in Arg7.

\subsection{Expression of genes related to starch synthesis in roots}

We selected six genes (MeFNR, Mendh, Meppc, MeLSU, MeUGP and MeInv) that encode key enzymes in the pathways of photosynthesis and starch accumulation to assess their expression in roots. All five genes were upregulated with the enlargement of storage roots in Arg7. The oxidized and reduced forms of the cofactors NAD (including $\mathrm{NAD}^{+}$and $\mathrm{NADH}$ ) and NADP (including $\mathrm{NADP}^{+}$and $\mathrm{NADPH}$ ) are fundamental mediators of various biological processes, including energy metabolism, mitochondrial functions, calcium homeostasis, the regulation of cellular redox potential, gene expression, pathogen defenses, aging and cell death ${ }^{[41]}$. The increased expression of MeFNR is consistent with increases in the rate of cellular metabolism from the early periods of root formation to the rapid enlargement of storage roots (Fig. 5a, Fig. 5b). The PEPC enzyme is important in regulating the metabolism of phosphorus and organic acids in roots ${ }^{[42,43]}$, and cassava AGPase is activated by 3phosphoglycerate and inhibited by up to $90 \%$ in the presence of inorganic phosphate ${ }^{[44]}$. Given that rates of expression of both Meppc and MeLSU were upregulated during the process of storage-root enlargement (Fig. $5 \mathrm{c}$, Fig. 5d), we speculated that there may be a synergistic relationship between Meppc and MeLSU. The expression of $\mathrm{MeUGP}$ appeared to reach a maximum when plants were around $200 \mathrm{~d}$ old, whereas the expression of MeInv was slightly lower at $200 \mathrm{~d}$ than that at $160 \mathrm{~d}$ in $\operatorname{Arg} 7$ storage roots (Fig. 5e, Fig. 5f). These observations may be attributable to the increase in the ratio of sucrose allocation to starch synthesis during the course of storage-root enlargement in Arg7. The observation that the highest expression level of MeInv was measured in Arg7 fibrous roots suggests that more sucrose was converted to glucose and fructose in fibrous roots than stored as starch.

Overall, photosynthetic efficiency was higher in Arg7 than in W14, and the proportion of photosynthesis products that were stored in leaf as temporary starch was less in Arg7 than in W14. All of the selected genes involved in starch synthesis were expressed at higher levels in Arg7 storage roots than in W14 storage roots. This might explain, at least in part, the higher starch content in Arg7 storage roots compared to W14 storage roots.

\section{Discussion}

\subsection{Value of the full-length cDNA library in cassava}

We constructed a library comprising 32640 full-length recombinant cDNA clones from cassava, and sequenced 6176 clones to generate 5067 EST sequences representing 1259 unigenes, which have been deposited in EST databases. Identification of cassava genes that encode either key enzymes in photosynthesis or starch metabolism, or regulators of these pathways, should greatly facilitate improvement of this important crop. Of the unigenes represented in the library, 746 unigenes were homologous to ESTs from model plants represented in the KEGG database, and 323 unigenes were mapped to 114 different pathways. In particular, 103 of the unigenes represented in our library are implicated in carbohydrate and energy metabolism, including the unigenes that encode RuBisCO, PEPC, pyruvate kinase, AGPase, starch synthase, trehalose-6-phosphate synthase, and ATP synthase. It has been reported that overexpression of AGPase, pyrophosphatase and NADH-glutamate synthase leads to increased root biomass in potato and cassava ${ }^{[39,45]}$. Some of the unigenes showing no similarity with other proteins in the database may be specific to cassava. It is possible that a few of them may simply represent untranslated regions or be too short to have domains that would present significant matches with other proteins, although we suspect that the majority of these genes define proteins specific to cassava or its close relatives. In summary, these gene resources in our library will contribute to the genetic improvement of cassava not only in terms of some critically important metabolic pathways but also to bolster ongoing efforts to assemble a complete gene catalog for this species.

It is noteworthy that some unigenes were mapped to KEGG metabolic pathways parallel to those in humans (Table 3). It is possible that some of the pathways have 

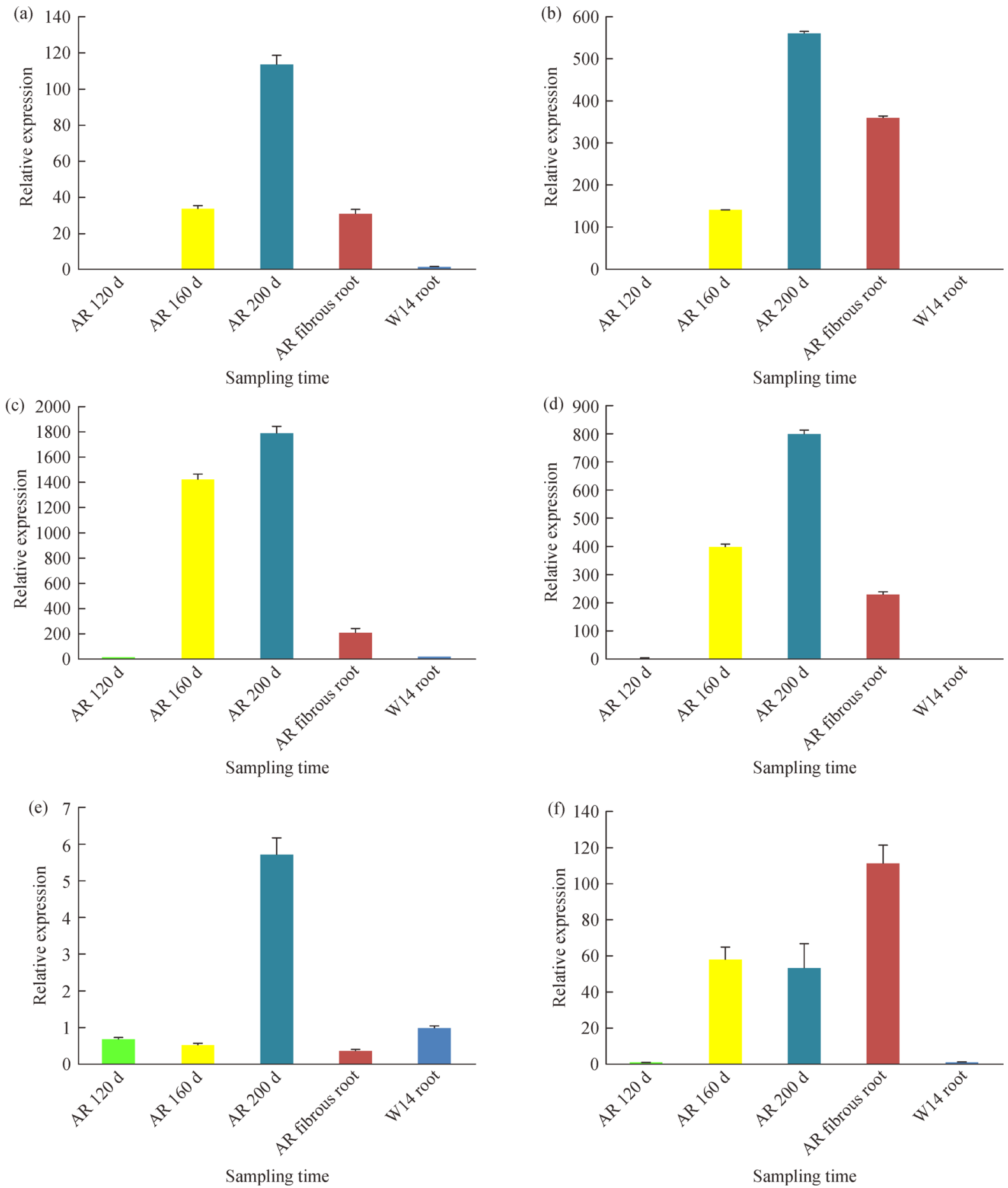

Fig. 5 Expression levels of selected genes implicated in photosynthesis and carbohydrate metabolism in cassava, using real-time PCR (a) MeFNR; (b) Mendh; (c) Meppc; (d) MeLSU; (e) MeUGP; (f) MeInv. Each data point represents the mean \pm SD of nine replicates, with values indicating fold-changes in relative gene expression following normalization relative to the actin cassava gene. AR $120 \mathrm{~d}$, AR $160 \mathrm{~d}$ and AR $200 \mathrm{~d}$ are levels in Arg7 storage roots 120, 160, and $200 \mathrm{~d}$ after planting, respectively.

common ancient origins dating to before the evolutionary divergence of plants and animals ${ }^{[46]}$. Recently, it was reported that the tomato $14-3-3$ protein 7 , a homolog of human protein 14-3-3e, regulates immunity-associated programmed cell death in tomato, and that both proteins share similar signaling transduction pathways dependent on phosphorylation ${ }^{[47]}$. Therefore, it will be valuable to investigate whether cassava has signaling pathways that parallel the functions of human signaling cascades.

Our full-length cDNA library was assembled from four 
sub-libraries in order to derive functional information through parallel comparisons of the compositions of the sub-libraries. There was no evidence of differential expression between W14 and Arg7 for 5067 of the ESTs in our library. These insights were enabled primarily by next generation sequencing technology, which can generate millions of reads in a relatively short time and at low cost, and is regarded as a powerful method to analyze the transcriptomes of eukaryotic genomes ${ }^{[48]}$. Despite the limited number of clones sequenced, we still obtained some valuable insights, related especially to carbohydrate and energy metabolism (Table 3). Therefore, in contrast to the stress-related full-length cDNA library for cassava published by BMC genomics ${ }^{[14]}$, our library was valuable in discovering the genes related to starch accumulation in cassava. At the same time, our library is the first EST collection of M. esculenta subsp. flabellifolia, an ancestral relative of cultivated cassava and will be useful to study evolution of the genus Manihot.

\subsection{Understanding of higher starch content in Arg7 storage roots}

Photosynthesis products are partly exported from chloroplasts as sucrose and partly turned into starch, a temporary energy store in chloroplasts, during the day ${ }^{[36]}$. Plastidic sucrose is partly transported into the vacuole and then cleaved into glucose and fructose, with the remainder transported to storage roots, which act as sink organs. There are two pathways for the transport of sucrose from leaves to sink organ cells. One is the pathway forming storage starch in amyloplasts, whereas the other is transport into the vacuole for cleavage into glucose and fructose for energy storage ${ }^{[49]}$.

Whereas cultivated cassava (M. esculenta) has several characteristics typical of $\mathrm{C}_{4}$ photosynthesis that are not usual for $\mathrm{C}_{3}$ plants ${ }^{[9,10,50]}$, wild Manihot species are incapable of $\mathrm{C}_{4}$ photosynthesis owing to the low activity of PEPC, the key enzyme of the $\mathrm{C}_{4}$ pathway ${ }^{[51]}$. In this study, the expression level of MePPC was higher than that in W14 and was at significant or very significant levels between 8 am and $2 \mathrm{pm}$. Moreover, Pn was higher in Arg7 than in W14 in 120, 160 and $200 \mathrm{~d}$ old plants (Fig. 3). In summary, photosynthetic efficiency is higher in Arg7 than in W14.

Activation of AGPase stimulates starch synthesis and decreases levels of glycolytic intermediates in leaves and storage roots ${ }^{[36,52]}$. In our study, the expression level of $\mathrm{MeLSU}$ was higher in leaves of W14 than in those of Arg7 throughout most of the day, especially from 4 to $6 \mathrm{pm}$ (Fig. 5e). Nonetheless, in $200 \mathrm{~d}$ old roots, the level of expression of MeLSU in Arg7 was nearly 800 times more than that in W14 (Fig. 5d). These data suggest that W14 temporarily stores more photosynthate as starch in leaves than $\operatorname{Arg} 7$, and the latter has a greater ability to synthesize starch in storage roots than W14.

\subsection{Starch accumulation in cassava}

The differential expression of the aforementioned genes that encode key enzymes involved in photosynthesis and starch synthesis possibly partly explains the differences in the efficiencies with which the two species accumulate starch in storage roots, although we cannot dismiss the possibility of regulation at the post-transcriptional level. Analysis of the promoters of these genes and the transcription factors that control their expression will be the focus of our future studies. For instance, a better understanding of the molecular basis that underlies the differential expression of $\mathrm{MeINV}$ and MeUGP in storage roots and fibrous roots may provide insights into the mechanism of sucrose allocation between organs with different functions.

Further research related to the pathway of starch accumulation metabolism in cassava should concentrate on both the regulation of the genes that encode key enzymes, the distribution of photosynthetic products throughout different parts of the plant, and the relationship between their transport and the accumulation of starch in roots. A first step toward this goal would involve evaluation of the expression profiles in different organs and under various conditions of the homologous genes detected within our library. This could be done through the construction of microarrays, for which once again, the availability of our full-length cDNA library would be an invaluable resource ${ }^{[53]}$.

\section{Conclusions}

Comparable full-length cDNA libraries of the leaves and storage roots of cultivar Arg7 and wild ancestor W14 were constructed with a total of 32640 recombinant clones. Primary annotation and expression validation revealed that Arg7 has a higher net photosynthesis rate and RuBPase activities than W14 in leaves, and has absolute higher starch accumulation efficiency than W14 in storage roots. This resource will provide bases for gene discovery, genome annotation and evolution in cassava.

Acknowledgements This work was supported by a National Nonprofit Institute Research Grant of CATAS-ITBB, and the earmarked fund for China Agricultural Research System (CARS-12). We thank Prof. Peng Zhang of Chinese Academy of Sciences for his constructive suggestions on this research.

Supplementary materials The online version of this article at http://dx. doi.org/10.15302/J-FASE-2016113 contains supplementary material (Appen$\operatorname{dix} \mathrm{A})$.

Compliance with ethics guidelines The authors Yang Zhang, Xin Chen, Haiyan Wang, Zhiqiang Xia, Peng Ling, and Wenquan Wang declare that they have no conflicts of interest or financial conflicts to disclose.

This article does not contain any studies with human or animal subjects performed by any of the authors. 


\section{References}

1. Taylor N, Chavarriaga P, Raemakers K, Siritunga D, Zhang P. Development and application of transgenic technologies in cassava. Plant Molecular Biology, 2004, 56(4): 671-688

2. de Souza C R B, Carvalho L J C B, de Mattos Cascardo J C. Comparative gene expression study to identify genes possibly related to storage root formation in cassava. Protein and Peptide Letters, 2004, 11(6): 577-582

3. Koch B, Sibbesen O, Swain E, Kahn R, Liangcheng D, Bak S, Halkier B, Møller B. Possible use of a biotechnological approach to optimize and regulate the content and distribution of cyanogenic glycosides in cassava to increase food safety. Acta Horticulturae, 1994, (375): 45-60

4. Siritunga D, Sayre R T. Domestication of cassava: generation of cyanogen-free cassava. Planta, 2003, 217(3): 367-373

5. Jansson C, Westerbergh A, Zhang J, Hu X W, Sun C. Cassava, a potential biofuel crop in the People's Republic of China. Applied Energy, 2009, 86(S1): S95-S99

6. Ziska L H, Runion G B, Tomecek M, Prior S A, Torbet H A, Sicher R. An evaluation of cassava, sweet potato and field corn as potential carbohydrate sources for bio-ethanol production in Alabama and Maryland. Biomass and Bioenergy, 2009, 33(11): 1503-1508

7. Hunt C A, Wholey D M, Cock J H. Growth physiology of cassava (Manihot esculenta Crantz). Field Crop Abstracts, 1977, 30: 77-89

8. Edwards G E, Sheta E, Moore B D, Dai Z, Fransceschi V R, Cheng $\mathrm{S} \mathrm{H}$, Lin C H, Ku M S B. Photosynthetic characteristics of cassava (Manihot esculenta), a $\mathrm{C}_{3}$ species with chlorenchymatous bundle sheath cells. Plant \& Cell Physiology, 1990, 31(8): 1199-1206

9. Angelov M N, Sun J, Byrd G T, Brown R H, Black C C. Novel characteristics of cassava, Manihot esculenta Crantz, a reputed $\mathrm{C}_{3}-$ $\mathrm{C}_{4}$ intermediate photosynthesis species. Photosynthesis Research, 1993, 38(1): 61-72

10. EI-Sharkawy M A. International research on cassava photosynthesis, productivity, eco-physiology, and responses to environmental stresses in the tropics. Photosynthetica, 2006, 44(4): 481-512

11. Osunsami A T, Akingbala J O, Oguntimein G B. Effect of storage on starch content and modification of cassava starch. Starch, 1989, 41 (2): $54-57$

12. Lopez C, Jorge V, Piegu B, Mba C, Cortes D, Restrepo S, Soto M, Laudie M, Berger C, Cooke R, Delseny M, Tohme J, Verdier V. An unigene catalogue of 5700 expressed genes in cassava. Plant Molecular Biology, 2004, 56(4): 541-554

13. Lokko Y, Anderson J V, Rudd S, Raji A, Horvath D, Mikel M A, Kim R, Liu L, Hernandez A, Dixon A G, Ingelbrecht I L. Characterization of an 18166 EST dataset for cassava (Manihot esculenta Crantz) enriched for drought-responsive genes. Plant Cell Reports, 2007, 26(9): 1605-1618

14. Sakurai T, Plata G, Rodriguez-Zapata F, Seki M, Salcedo A, Toyoda A, Ishiwata A, Tohme J, Sakaki Y, Shinozaki K, Ishitani M. Sequencing analysis of 20,000 full-length cDNA clones from cassava reveals lineage specific expansions in gene families related to stress response. BMC Plant Biology, 2007, 7: 66

15. Li Y Z, Pan Y H, Sun C B, Dong H T, Luo X L, Wang Z Q, Tang J L, Chen B. An ordered EST catalogue and gene expression profiles of cassava (Manihot esculenta) at key growth stages. Plant Molecular
Biology, 2010, 74(6): 573-590

16. Robert J S, Michael E S. RUBISCO: structure, regulatory interactions, and possibilities for a better enzyme. Annual Review of Plant Biology, 2002, 53(4): 449-475

17. Allen J F. Oxygen reduction and optimum production of ATP in photosynthesis. Nature, 1975, 256(5518): 599-600

18. Bandyopadhyay A, Datta K, Zhang J, Yang W, Raychaudhuri S, Miyao M, Datta S K. Enhanced photosynthesis rate in genetically engineered indica rice expressing pepc gene cloned from maize. Plant Science, 2007, 172(6): 1204-1209

19. Chollet R, Vidal J, O'Leary M H. Phosphoenolpyruvate carboxylase: a ubiquitous, highly regulated enzyme in plants. Annual Review of Plant Physiology and Plant Molecular Biology, 1996, 47 (1): 273-298

20. Yoshihara N, Imayama T, Fukuchi-Mizutani M, Okuhara H, Tanaka Y, Ino I, Yabuya T. cDNA cloning and characterization of UDPglucose: anthocyanidin 3-O-glucosyltransferase in Iris hollandica. Plant Science, 2005, 169(3): 496-501

21. Tomlinson P T, Duke E R, Nolte K D, Koch K E. Sucrose synthase and invertase in isolated vascular bundles. Plant Physiology, 1991, 97(3): 1249-1252

22. Fernie A R, Willmitzer L, Trethewey R N. Sucrose to starch: a transition in molecular plant physiology. Trends in Plant Science, 2002, 7(1): 35-41

23. Kleczkowski L A. Is leaf ADP-glucose pyrophosphorylase an allosteric enzyme? Biochimica et Biophysica Acta (BBA)-Protein Structure and Molecular Enzymology, 2000, 1476(1): 103-108

24. Kleczkowski L A. A new player in the starch field. Plant Physiology and Biochemistry, 2001, 39(9): 759-761

25. Stam M, Mol J N M, Kooter J M. The silence of genes in transgenic plants. Annals of Botany, 1997, 79(1): 3-12

26. Zhu Y Y, Machleder E M, Chenchik A, Li R, Siebert P D. Reverse transcriptase template switching: a SMART ${ }^{\mathrm{TM}}$ approach for fulllength cDNA library construction. BioTechniques, 2001, 30(4): 892-897

27. Ewing B, Green P. Base-calling of automated sequencer traces using Phred. II. Error probabilities. Genome Research, 1998, 8(3): 186194

28. Ewing B, Hillier L D, Wendl M C, Green P. Base-calling of automated sequencer traces using Phred. I. Accuracy assessment. Genome Research, 1998, 8(3): 175-185

29. Zhang Z, Schwartz S, Wagner L, Miller W.A greedy algorithm for aligning DNA sequences. Journal of Computational Biology, 2000, 7(1-2): 203-214

30. Huang X, Madan A. CAP3: a DNA sequence assembly program. Genome Research, 1999, 9(9): 868-877

31. Pertea G, Huang X, Liang F, Antonescu V, Sultana R, Karamycheva S, Lee Y, White J, Cheung F, Parvizi B, Tsai J, Quackenbush J. TIGR gene indices clustering tools (TGICL): a software system for fast clustering of large EST datasets. Bioinformatics, 2003, 19(5): 651-652

32. Camon E, Barrell D, Lee V, Dimmer E, Apweiler R. The gene ontology annotation (GOA) database-an integrated resource of GO annotations to the UniProt knowledgebase. In Silico Biology, 2004, 4(4): 5-6

33. El-Sharkawy M A, Cock J H, de Cadena G. Influence of differences 
in leaf anatomy on net photosynthetic rates of some cultivars of cassava. Photosynthesis Research, 1984, 5(3): 235-242

34. Mullikin J C, McMurray A A. Sequencing the genome, fast. Science, 1999, 283(5409): 1867-1868

35. Angelov M N, Sun J, Byrd G T, Brown R H, Black C C. Novel characteristics of cassava, Manihot esculenta Crantz, a reputed $\mathrm{C}_{3}-$ $\mathrm{C}_{4}$ intermediate photosynthesis species. Photosynthesis Research, 1993, 38(1): 61-72

36. Zeeman S C, Smith S M, Smith A M. The diurnal metabolism of leaf starch. Biochemical Journal, 2007, 401(1): 13-28

37. Zeeman S C, Kossmann J, Smith A M. Starch: its metabolism, evolution, and biotechnological modification in plants. Annual Review of Plant Biology, 2010, 61(1): 209-234

38. Estruch J J, Beltrán J P. Change in invertase activities precede ovary growth induced by gibberellic acid in Pisum sativum. Physiologia Plantarum, 1991, 81(3): 319-326

39. Geigenberger P, Stitt M. Diurnal changes in sucrose, nucleotides, starch synthesis and AGPs transcript in growing potato tubers that are suppressed by decreased expression of sucrose phosphate synthase. Plant Journal, 2000, 23(6): 795-806

40. Gerhardt R, Stitt M, Heldt H W. Subcellular metabolite levels in spinach leaves. Plant Physiology, 1987, 83(2): 399-407

41. Ying $\mathrm{W} H$. $\mathrm{NAD}^{+} / \mathrm{NADH}$ and $\mathrm{NADP}^{+} / \mathrm{NADPH}$ in cellular functions and cell death: regulation and biological consequences. Antioxidants \& Redox Signalling, 2008, 10(2): 179-206

42. Schulze J, Shi L F, Blumenthal J, Samac D A, Gantt J S, Vance C P. Inhibition of alfalfa root nodule phosphoenolpyruvate carboxylase through an antisense strategy impacts nitrogen fixation and plant growth. Phytochemistry, 1998, 49(2): 341-346

43. Begum H H, Osaki M, Shinano T, Miyatake H, Wasaki J, Yamamura $T$, Watanabe $T$. The function of a maize-derived phosphoenol pyruvate carboxylase (PEPC) in phosphorus-deficient transgenic rice. Soil Science and Plant Nutrition, 2005, 51(4): 497 506

44. Munyikwa T, Kreuze J, Fregene M, Suurs L, Jacobsen E, Visser R.
Isolation and characterisation of cDNAs encoding the large and small subunits of ADP-glucose pyrophosphorylase from cassava (Manihot esculenta Crantz). Euphytica, 2001, 120(1): 71-83

45. Ihemere U, Arias-Garzon D, Lawrence S, Sayre R. Genetic modification of cassava for enhanced starch production. Plant Biotechnology, 2006, 4(4): 453-465

46. Ausubel F M. Are innate immune signaling pathways in plants and animals conserved? Nature Immunology, 2005, 6(10): 973-979

47. Oh C S, Pedley K F, Martin G B. Tomato 14-3-3 protein 7 positively regulates immunity-associated programmed cell death by enhancing protein abundance and signaling ability of MAPKKK $\alpha$. Plant Cell, 2010, 22(1): 260-272

48. Wang Z, Gerstein M, Snyder M. RNA-Seq: a revolutionary tool for transcriptomics. Nature Reviews Genetics, 2009, 10(1): 57-63

49. Azcón-Bieto J, Lambers H, Day D A. Effect of photosynthesis and carbohydrate status on respiratory rates and the involvement of the alternative pathway in leaf respiration. Plant Physiology, 1983, 72 (3): 598-603

50. El-Sharkawy M A, Cock J H, Held A A. Photosynthetic responses of cassava cultivars (Manihot esculenta Crantz) from different habitats to temperature. Photosynthesis Research, 1984, 5(3): 243250

51. Tiessen A, Hendriks J H M, Stitt M, Branscheid A, Gibon Y, Farré E $\mathrm{M}$, Geigenberger $\mathrm{P}$. Starch synthesis in potato tubers is regulated by post-translational redox modification of ADP-Glucose pyrophosphorylase: a novel regulatory mechanism linking starch synthesis to the sucrose supply. Plant Cell, 2002, 14(9): 2191-2213

52. Calatayud P A, Barón C H, Velásquez H, Arroyave J A, Lamaze T. Wild Manihot species do not possess $\mathrm{C}_{4}$ photosynthesis. Annals of Botany, 2002, 89(1): 125-127

53. Seki M, Narusaka M, Abe H, Kasuga M, Yamaguchi-Shinozaki K, Carninci P, Hayashizaki Y, Shinozaki K. Monitoring the expression pattern of 1300 Arabidopsis genes under drought and cold stresses by using a full-length cDNA microarray. Plant Cell, 2001, 13(1): $61-72$ 